\title{
Cervical Serous Adenocarcinoma
}

National Cancer Institute

\section{Source}

National Cancer Institute. Cervical Serous Adenocarcinoma. NCI Thesaurus. Code

C40201.

A rare adenocarcinoma that arises from the cervix. It is characterized by the presence of papillary patterns and cellular budding. Psammoma bodies are often seen. 